\section{INCREASED PERIOPERATIVE MORTALITY IN ELECTIVE CORONARY ARTERY BYPASS GRAFTING AFTER PREVIOUS PERCUTANEOUS CORONARY INTERVENTION}

\section{To the Editor:}

The article by Bonaros and colleagues, ${ }^{1}$ which clearly establishes the relationship between increased perioperative complications and mortality in patients with previous elective percutaneous coronary intervention (PCI) who underwent further elective coronary artery bypass grafting (CABG), reinforces the hypothesis stemming from pathophysiologic changes elicited by stent insertion. ${ }^{2}$ The study findings are very remarkable, and some additional explanations for these outcomes are offered herein.

The authors studied 306 consecutive patients who underwent CABG after previous elective $\mathrm{PCI}$, and roughly one third of the patients experienced myocardial infarction (MI) at the interval between PCI and CABG. Remarkably, this finding has been unveiled in the meta-analysis of randomized trials comparing PCI with conservative medical treatment in patients with stable coronary artery disease by Katritsis and Ioannidis, ${ }^{3}$ in which there was a trend for more nonfatal MI in patients who underwent PCI, suggesting an approximately $30 \%$ increase in the relative risk of nonfatal MI with PCI. Coronary stenting appears to cause an intense and sustained coronary artery inflammatory response in the vessel wall,

\footnotetext{
The Editor welcomes submissions for possible publication in the Letters to the Editor section that consist of commentary on an article published in the Journal or other relevant issues. Authors should: • Include no more than 500 words of text, three authors, and five references. • Type with double-spacing. $\bullet$ See http://jics.ctsnetjournals.org/misc/ifora.shtml for detailed submission instructions. - Submit the letter electronically via jtcvs.editorialmanager.com. Letters commenting on an article published in the JTCVS will be considered if they are received within 6 weeks of the time the article was published. Authors of the article being commented on will be given an opportunity of offer a timely response ( 2 weeks) to the letter. Authors of letters will be notified that the letter has been received. Unpublished letters cannot be returned.
}

and a large body of evidence links inflammatory mechanisms to atheromatous plaque destabilization, leading to plaque rupture and coronary events.

Furthermore, ejection fraction was found to be lower in the PCI group when compared with that seen in the non-PCI group. Apart from the higher rate of MI in the PCI group, periprocedural PCI-induced myocardial injury might play an important role in this outcome, with an acute ischemic process triggered by several factors related to the stent implantation procedure. ${ }^{2}$

An approximately 4-fold increase in the incidence of perioperative MI was observed in the PCI group, which was associated with a significantly higher incidence of low cardiac output syndrome and perioperative mortality compared with that seen in the non-PCI group. In this particular aspect one cannot neglect the role of a PCI-induced sustained inflammatory reaction leading to perennial endothelial dysfunction, inducing stent thrombosis, and, more importantly, adversely affecting early and long-term graft patency. This issue remains significantly overlooked, and further studies are urgently required to elucidate this question.

Therefore data from the study by Bonaros and colleagues ${ }^{1}$ help to substantiate and unquestionably justify the former premise that $\mathrm{CABG}$ might not provide equivalent outcomes in patients with previous stenting.

Walter J. Gomes, MD, PhD Cardiovascular Surgery Escola Paulista de Medicina-Federal University of São Paulo São Paulo, Brazil

\section{References}

1. Bonaros N, Hennerbichler D, Friedrich G, Kocher A, Pachinger O, Laufer G, et al. Increased mortality and perioperative complications in patients with previous elective percutaneous coronary interventions undergoing coronary artery bypass surgery. $J$ Thorac Cardiovasc Surg. 2009;137:846-52.

2. Gomes WJ, Buffolo E. Coronary stenting and inflammation: implications for further surgical and medical treatment. Ann Thorac Surg. 2006;81:1918-25.

3. Katritsis DG, Ioannidis JP. Percutaneous coronary intervention versus conservative therapy in nona-
}

cute coronary artery disease: a meta-analysis Circulation. 2005;111:2906-12.

doi:10.1016/j.jtcvs.2009.04.054

\section{Reply to the Editor:}

Gomes ${ }^{1}$ hypothesizes that percutaneous coronary interventions (PCIs) with coronary stents aggravate local and systemic inflammatory reactions, which might be responsible for major coronary events, such as plaque rupture and myocardial infarction. Based on our findings, $33 \%$ of the patients studied had a history of myocardial infarction during the interval between PCI and coronary artery bypass grafting. ${ }^{2}$ According to the results of the SYNTAX trial, $4.4 \%$ of the patients treated with PCI had a periprocedural major adverse cardiac event. ${ }^{3}$ Long-term events could be attributed to stent thrombosis as a result of inflammatory reaction, insufficient antiplatelet therapy, or resistance to clopidogrel therapy, aspirin therapy, or both. ${ }^{4}$ Although more than one third of the patients undergoing PCI were treated with drug-eluting stents, the incidence of target lesion revascularization was quite high $(19 \%)$ in these series. A local inflammatory reaction can result in platelet and leukocyte activation, as well as plaque destabilization, the effects of which might extend to the target vessel. ${ }^{5}$

Nikolaos Bonaros, MD, PhD

Dominik Wiedemann, $M D$

Thomas Schachner, $M D$

Alfred Kocher, $M D$

Cardiac Surgery

Innsbruck Medical University

Innsbruck, Austria

\section{References}

1. Gomes WJ. Increased perioperative mortality in elective coronary artery bypass grafting after previous percutaneous coronary intervention. $J$ Thorac Cardiovasc Surg. 2009; 138:1253.

2. Bonaros N, Hennerbichler D, Friedrich G, Kocher A, Pachinger O, Laufer G, et al. Increased mortality and perioperative complications in patients with previous elective percutaneous coronary interventions undergoing coronary artery bypass surgery. $J$ Thorac Cardiovasc Surg. 2009;137:846-52.

3. Serruys PW, Morice M-C, Kappetein P, Colombo A, Holmes DR, Mack MJ, et al. Percutaneous coronary intervention versus coronary-artery 
bypass grafting for severe coronary artery disease. $N$ Engl J Med. 2009;360:961-72.

4. Gawaz M, Geisler T. Coronary artery disease: platelet activity: an obstacle for successful PCI. Nat Rev Cardiol. 2009;6:391-2.

5. Inoue $\mathrm{T}$, Komoda $\mathrm{H}$, Kotooka $\mathrm{N}$, Morooka $\mathrm{T}$, Fujimatsu D, Hikichi Y, et al. Increased circulating platelet-derived microparticles are associated with stent-induced vascular inflammation. Atherosclerosis. 2008;196:469-76.

doi:10.1016/j.jtcvs.2009.07.005

\section{AORTIC STENOSIS AND \\ STATINS}

To the Editor:

The meta-analysis by Takagi and coworkers ${ }^{1}$ addresses the effect of statins on aortic stenosis. The authors conclude that statins do retard the progression of aortic stenosis by retarding the increase in peak aortic jet velocity (PAJV) but not reducing the decrease in aortic valve area (AVA). The recent publication of the Simvastatin and Ezetimibe in Aortic Stenosis (SEAS) study $^{2}$ prompted us to do a metaanalysis on the same question to see whether there is any difference in the summary estimate. During this process, we realized that there were some errors in the calculation of the summary estimate. In brief, the units had been mixed in the calculations.

The data for AVA and PAJV for the Bellamy ${ }^{3}$ and Mohler ${ }^{4}$ studies were ex- pressed as percentage change per year, whereas for the rest of the studies, the PAJV was in meters per second per year, and for AVA, it was in square meters per year. It was almost impossible to create a Forrest plot with their data, and the percentage data became huge and far away from the rest of the studies, which became almost invisible dots in the figure. This must have prompted the authors to use the standardized mean difference in figures.

We corrected this mistake by projecting the AVA and PAJV change per year using the baseline values and percentage change data expressed in the original articles (Figures 1 and 2).

Annualised increase in PAJV (Mean Difference)

\begin{tabular}{llrccccc} 
Model & Study name & \multicolumn{3}{c}{ Statistics for each study } & & & Sample size \\
\cline { 3 - 6 } & & $\begin{array}{c}\text { Difference } \\
\text { in means }\end{array}$ & $\begin{array}{c}\text { Lower } \\
\text { limit }\end{array}$ & $\begin{array}{c}\text { Upper } \\
\text { limit }\end{array}$ & p-Value & Group-A & Group-B \\
Rossebo et al & -0.010 & -0.038 & 0.018 & 0.480 & 943 & 929 \\
Moura et al & -0.200 & -0.322 & -0.078 & 0.001 & 61 & 60 \\
Cowell et al & -0.004 & -0.075 & 0.067 & 0.912 & 65 & 69 \\
& Antonini - C et al Subgroup1 & -0.010 & -0.085 & 0.065 & 0.793 & 63 & 63 \\
$\quad$ Antonini - C et al subgroup2 & -0.010 & -0.133 & 0.113 & 0.873 & 32 & 32 \\
& Rosenhek et al & -0.290 & -0.423 & -0.157 & 0.000 & 50 & 161 \\
& Bellamy et al & -0.130 & -0.252 & -0.008 & 0.036 & 38 & 118 \\
Random & -0.078 & -0.144 & -0.012 & 0.021 & &
\end{tabular}

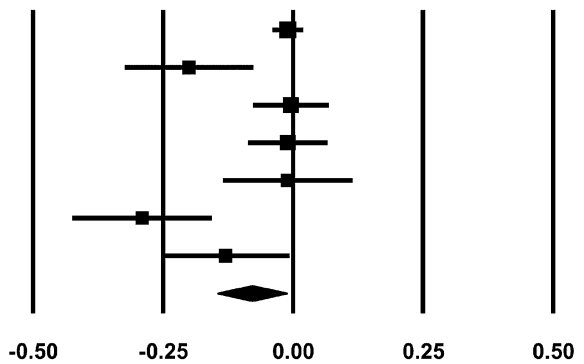

Favours Statins Favours Control

FIGURE 1. Annualized increase in peak aortic jet velocity ( $P A J V$; mean difference).

\section{Annualised Decrease in AVA (Mean Difference)}

\begin{tabular}{llrrrr} 
Model & Study name & \multicolumn{4}{c}{ Statistics for each study } \\
\cline { 3 - 4 } & $\begin{array}{r}\text { Difference } \\
\text { in means }\end{array}$ & $\begin{array}{c}\text { Lower } \\
\text { limit }\end{array}$ & $\begin{array}{c}\text { Upper } \\
\text { limit }\end{array}$ & p-Value \\
Rossebo et al & 0.000 & -0.028 & 0.028 & 1.000 \\
Mohler et al & 0.170 & 0.040 & 0.300 & 0.011 \\
Moura et al & -0.050 & -0.088 & -0.012 & 0.010 \\
Cowell et al & -0.124 & -0.181 & -0.067 & 0.000 \\
Bellamy et al & -0.130 & -0.190 & -0.070 & 0.000 \\
& Novaro et al & -0.050 & -0.105 & 0.005 & 0.075 \\
Random & & -0.045 & -0.100 & 0.010 & 0.106
\end{tabular}

\begin{tabular}{cc}
\multicolumn{2}{c}{ Sample size } \\
Group-A & Group-B \\
943 & 929 \\
39 & 22 \\
61 & 60 \\
65 & 69 \\
38 & 118 \\
57 & 117
\end{tabular}

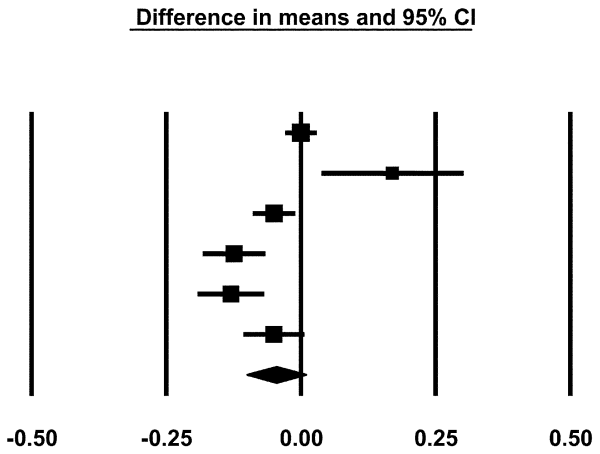

Favours Statins Favours Control

FIGURE 2. Annualized decrease in aortic valve area ( $A V A$; mean difference). 